The reference for this paper is:

Middleton, C. A., Scheepers, H., \& Cukier, W. (2005). Exploring the Contradictions of Mobility: A Case Study of BlackBerry Users in Canada. In Thong, J. Y. L. \& Tam, K. Y. (Eds.), Proceedings of the Hong Kong Mobility Roundtable (pp. 299-309). Hong Kong: HKUST. 


\title{
Exploring the Contradictions of Mobility: A Case Study of BlackBerry Users in Canada
}

\author{
Catherine A. Middleton \\ School of Information Technology Management \\ Ryerson University, Toronto, Canada \\ Helana Scheepers \\ School of Information Management and Systems \\ Monash University, Victoria, Australia \\ Wendy Cukier \\ School of Information Technology Management \\ Ryerson University, Toronto, Canada
}

\begin{abstract}
Blackberries, mobile technology with limited functionality, have been adopted rapidly by users. Few studies about the Blackberry technology explore the apparent addiction that users have for this technology. Our study explores users' perceptions about the device and how it impacts on their day to day life. The participants of the study consist of users currently using Blackberry devices and users that chose to return their Blackberries after a short use period. The study highlights the apparent contradictions inherent in working in an environment with anytime anywhere connectivity. The study highlights the need for future research in the changes that the use of mobile devices such Blackberries has on the day to day life of users.
\end{abstract}

Keywords: Mobile internet, BlackBerry, Mobility, Connectivity, Canada

\section{Introduction}

This paper presents the results of a study of BlackBerry users. The BlackBerry is a handheld PDA that provides e-mail, internet and phone capabilities. It is similar to other mobile communication devices on the market, but does not offer the range of features found on today's mobile phones (e.g. camera, MP3 player), nor does it offer the functionality of pocket PCs. The BlackBerry differs from many e-mail enabled mobile phones and PDAs because it has a full QWERTY keyboard.

This research is motivated by a desire to understand the rapid adoption rate of BlackBerries. At the end of 2004, there were more than one million BlackBerry users around the world, a number that has doubled since 2003 (Research in Motion, 2004). In April 2005, there are an estimated 2.5 million BlackBerry users, and this rapid growth rate is expected to continue (Avery, 2005). While this number is tiny in comparison to 1.32 billion mobile phone users worldwide (International Telecommunication Union, 2004), the BlackBerry's features make it worth studying. The functionality of the BlackBerry is quite limited when compared to the newest devices on the market in Asia and Europe, yet it is the communication device of choice within many business and government organizations in North America (Applewhite, 2002).

The BlackBerry was developed by Canadian company Research in Motion (RIM), and Canadians have been early adopters of the device. When the BlackBerry came on the market in Canada in 1999 good alternative means of sending and receiving e-mail on a handheld mobile device were not available. Canadian adoption of mobile telephony still lags that in Europe and Asia (International Telecommunication Union, 2004), and Canadians have not embraced SMS messaging for business usage. Although there are now many options for 
mobile internet and e-mail access in Canada, the BlackBerry has had a first mover advantage in the Canadian market for mobile devices, resulting in very strong market share in Canada.

This paper presents data collected in interviews with Canadian BlackBerry users, offering insights on how this specific device is used, as well as a more general perspective on the use of mobile devices in the work environment. It demonstrates that BlackBerry-based mobile communication does appear to have some differences as compared to other types of mobile communication. The paper outlines contradictory expectations of workplace mobility. It describes three ways that BlackBerries are used to create a mobile work environment for their users, and discusses the nature of this anytime, anywhere communication environment. The paper counters the perspective that BlackBerries are addictive devices, noting that they tend to reinforce existing work habits rather than create new behaviours among their users. However, the data presented here do show that the users of this device find it difficult to disconnect from their work.

\section{Literature Review and Research Questions}

Previous research on mobile communication has not tended to be device specific, focusing instead on categories of devices like mobile phones. Given that the BlackBerry has less functionality than other devices yet appears to be highly valuable for its users, we believe that it is important to begin this research by gaining a better understanding of the device itself. The first research question this paper addresses is "Does a BlackBerry differ from other handheld mobile communication devices, and if so, how?"

We are not aware of any recent academic research studying BlackBerry users. Dunnavant (2001) reports the results of a six month trial of BlackBerries in a technical support context, focusing on the functionality of the devices, and concluding that the cost of the devices could not be justified for a wide scale deployment in the organization where the trial took place. Churchill and Wakeford (2002) present results from a study of two researchers using BlackBerries in 1999 and 2000. They report problems of unreliable connectivity and lack of critical mass, issues that have largely disappeared as the device has become widely used. Other researchers acknowledge the presence of BlackBerries within organizations, but do not go beyond a cursory mention of the existence of the devices (e.g. Elderfield, 2003; Nah, Siau, \& Sheng, 2005).

While there is little academic research on BlackBerries, they are gaining frequent mention in the popular press in North America and Europe, and public awareness of the devices is growing. In the UK, BlackBerry usage has been banned in the House of Commons (BBC News, 2005). Air Canada staff specifically instruct passengers to "turn off BlackBerries" and other mobile devices before takeoff. A recent episode of the popular US television show CSI: Miami featured a BlackBerry prominently (Shaw, 2005), and television host Oprah Winfrey put the BlackBerry on her list of favourite things. BlackBerries are even used at the Vatican, with one reporter noting that prior to entering the conclave to elect the new Pope, cardinals would be "sworn to secrecy and X-rayed and swept electronically for cellphones and BlackBerry devices" (Saunders, 2005).

The adoption of BlackBerries by cardinals and celebrities is not of particular interest in this paper, these examples merely highlight the growing awareness of the device. What is of interest is how the usage of BlackBerries impacts the adopters, and the organizations and personal environments in which they operate. The BlackBerry's "always on, always connected ${ }^{\circledR}$ " functionality is thought to be so addictive to many users that it has been labelled a "crackberry" (Libin, 2001), serving to blur, or even obliterate, boundaries between work and personal time. As Gibson (2005) observes, the deployment patterns for BlackBerries within organizations generally ensure that an individual with a BlackBerry has a boss with a 
BlackBerry, frequently resulting in an expectation that that individual will be available, by BlackBerry, whenever the boss sends a message, 24/7. The BlackBerry also extends an organization's reach into employees' vacation time, such that "when an employee [with a BlackBerry] leaves the office for vacation or business travel, there is no longer much need to designate a colleague to take over" (Tugend, 2004).

The media suggest that BlackBerry users face many contradictory expectations in their daily interaction with their devices. Among them are i) the benefits of always being able to keep in touch with the office versus the resentment caused when the office intrudes on personal time and space; ii) the sense of urgency created by "push" e-mail versus its impact on concentration and completing tasks; and iii) the freedom to work away from the office versus working in inappropriate situations (e.g. thumb typing while driving a car or at a dinner party). It appears that there are many concerns about the adoption of BlackBerries that are worthy of further investigation. The second research question this paper addresses has two parts: Do users acknowledge the contradictory expectations created by their BlackBerry usage? How do users manage the contradictions?

\section{Methodology}

The paper presents data collected in 16 semi-structured interviews. We have interviewed 13 BlackBerry users, 1 Treo user (a device with similar functionality to the BlackBerry), and 2 individuals who have chosen not to adopt BlackBerries despite working in situations where BlackBerry usage is widespread. Our participants (3 female, 13 male) work in a wide variety of industries, including construction, law, telecommunications, professional sports management, pharmaceuticals, information technology consultancy, and insurance. We also interviewed people who work in universities, government, and public security. Participants ranged in age from mid-20s to mid-50s, and represent all levels of the corporate hierarchy, from entry level positions to CEOs. Geographically, our participants work in large Canadian cities, including Toronto, Mississauga, Ottawa, Montreal and Regina. Many are frequent travellers, within Canada and beyond. One participant has had a BlackBerry for less than three months, several have used a BlackBerry for more than four years.

All interviews were conducted by the first author in early 2005. Interviews were recorded and professionally transcribed. A coding scheme was developed based on the research questions, and transcripts were coded using N6 software. The date presented here come directly from the informant interviews. In some cases quotes have been edited to improve readability, without changing the speaker's intent.

It should be noted that this paper reports on an ongoing research project. As a result, the findings presented here are preliminary and primarily descriptive, and set the stage for further theoretical analysis as the project progresses.

\section{Findings}

\subsection{Are BlackBerries Different?}

The first research question this paper addresses is "Does a BlackBerry differ from other handheld mobile communication devices, and if so, how?" Our data indicate that BlackBerry users do think that their BlackBerries are different than other devices.

There has been no other individual technology that I think has shaped me as much as BlackBerry. I've arranged my life quite differently because of BlackBerry, and I'm not quite certain what I would have done instead - sort of having to think all that through - but I'm quite convinced that I would not be working the way I am now, and I wouldn't have arranged how I do my work in a similar way if it were not for a technology like BlackBerry. (CEO, insurance 
industry)

One aspect of the difference is that users can create a sense of immediacy in their e-mail interactions with clients and colleagues.

If I send someone an e-mail they think I'm at my desk. I'd like it that I were out on the golf course, but more likely I'm doing another task. But because of what we do and because we do very high-end residential projects for very demanding clients - professional people, usually - they like to think that we're doing just their job, and that all 52 of us are doing just... now, they know in the back of their mind that that's impossible, and that I have to run ten other jobs, but each of them want to think that the owner's looking at every detail. And if they can send me an e-mail and I can respond to it, or if I can be proactive - which is even better - and get the information from somebody or be on-site and send them a little note, that's a wonderful thing. (Owner, construction firm)

Several users also noted that there is an "emerging social protocol" related to providing direct access to certain individuals who would previously have had assistants screening their e-mail.

I've just started to notice that if I give my BlackBerry address to a politician more often than not there'll be kind of a pause, and then they'll give me... they're making a decision, they're making a decision between giving me their BlackBerry - which means we're giving each other very direct access, with no staff interference - or they'll give me what is an office e-mail, which we both know is monitored by staff. So it's kind of an unspoken indicator of a level of trust or a level of interest when someone reciprocates with a BlackBerry. (Lawyer)

It is true that there are other devices that provide very similar functionality to the BlackBerry, but in the Canadian context these devices are not as well-recognized or understood. As the Treo user we interviewed noted, if someone asks her if her device is a phone, and she responds that it is a Treo "they wouldn't have a clue what that is, but if I said it's like a BlackBerry, [they say] 'Oh!' So BlackBerry's got the word out there as an identifier". Another user confirms that BlackBerries are recognized and convey expectations around communication response times. A political consultant joked that he "became known as the guy who could respond to an e-mail almost before they pushed send."

They've done a wonderful marketing job, I think, in that anyone that sees that I have a BlackBerry, it always demands... it never demands disrespect, it always demands a certain amount of respect, in that they think, "Okay, maybe he's not really a high-tech wizard or anything but he seems to value communication, he seems to value timeliness." (Construction industry)

Other people we spoke with were more explicit about the expectations of response times in organizations. A non-user told of a lunch with a friend where:

she answered seven BlackBerry messages in an hour and fifteen minutes. I said to her - she's an old associate, full vice-president in a technology company "What are you doing? Dan will wait." Dan is her CEO. She said, "I'm expected to answer in ten minutes." "What?!?" "I'm expected to answer in ten minutes, 24/7."

For another user (working for a professional sports team):

There's no excuse not to get back to somebody if you have a BlackBerry, and that's the problem, whereas for a cell phone if you leave a message you can say, "Well, I got the message an hour later because I was in a meeting," but if you have a BlackBerry and someone PINs you there's no excuse to not return it. 
Asked about the expected response time when someone "berries him", the same user responded:

Right away. That's the whole concept of it, is the urgency of the message.

Usually when someone sends you a BlackBerry they're either not at their desk

or they're in a meeting and need an answer in that meeting right away.

This user's comments also demonstrate the language that has emerged among BlackBerry users. In his organization, people send "berries", and "PIN" each other (direct BlackBerry to BlackBerry messaging).

The data above provide some indication that users believe that BlackBerries do differ from other handheld communication devices. It is true that the basic functionality described here is readily available through other handheld devices, but it appears that BlackBerry usage conveys certain meaning that is not apparent with other devices. Specifically, the BlackBerry allows direct, unmediated e-mail interaction with its users, and BlackBerry messaging conveys an urgency not present in other e-mail communication.

BlackBerries also differ from similar devices in their ease of use. Many respondents noted that although they could find other ways to carry out mobile communication, none were as straight forward as the BlackBerry. Asked about using the device outside Canada, respondents indicated it worked "perfectly", "seamlessly", and "just hooked up automatically". (There were some people who had trouble making network connections outside the country, but they noted that the problem was with their service provider, not with the device itself.) The general consensus was that BlackBerries are simple and easy to use, "it just all works."

It's just so easy to use. One of the reasons I've put off getting one for such a long time was a fear that it was going to be difficult to operate. ...Well, it was like a five-page instruction manual. It was the easiest thing to set up and use I've ever done recently, that's for sure. (CEO, technology industry)

In contrast to a lot of other emerging technology over the last little while it simply does what needs to be done. You don't worry about it or go look it up. ...I'm quite impressed that it just works and I don't have to go struggling with it. (CEO, insurance)

\subsection{Recognizing the Contradictions of BlackBerry Use}

Media coverage of BlackBerries frequently focuses on the negative aspects of always on connectivity. As was noted above, BlackBerry usage often creates certain expectations regarding rapid response times and constant availability, meaning that it is difficult for users to disconnect from their jobs.

The first part of our second research question asks whether users acknowledge the contradictions in their BlackBerry usage. The answer to this is a resounding yes. Every single person interviewed made some reference to the challenges of integrating the device into his or her life in appropriate ways. Examples of these challenges are presented below.

Many users commented that friends and family found the devices annoying, and wished that the users would turn them off.

Sometimes my husband says, "Would you leave that thing alone!" (university administrator, Treo user)

It's not so much I get annoyed by it as a leash, it's more friends or my girlfriend will get upset. "Put the BlackBerry away! Let's watch the TV show," you know. (IT consultant)

But users seem compelled to check their BlackBerries night and day:

I check the thing before I go to bed at night, and I check the first thing in the morning, and I would never, ever do that with my computer. I would never log on and check my e-mail at home before I went to bed or when I got up in the 
morning. (Pharmaceutical manager)

Users know that checking the BlackBerry well outside office hours is probably unnecessary, but feel reassured that they are not missing something important.

It's intrusive. There's no question about it. ... I've found myself - I probably shouldn't say this, but I will - I've found myself on my own birthday checking emails at 10:30 at night, 11 o'clock at night. My wife's saying, "What's wrong with you?" There's a reason it's called a Crackberry. But I guess the reverse is I'm never concerned or cause concern to myself that I'm not available to meet whatever situation occurs. (Public security official)

It's comfort food for a techno guy. I find it makes me feel connected and I'm able to respond fast to issues, it makes me feel that I'm on top of issues, so it gives me a greater sense of confidence that I'm managing, doing my job. (university administrator)

Most users have been in meetings where they, or someone else, is using a BlackBerry. Respondents have mixed feelings about this sort of behaviour. The quote below reflects this discomfort with the behaviour, while acknowledging that sometimes it is necessary.

I sort of fall on the side of the ledger that says if you're at the meeting you should be participating in the meeting, not using your BlackBerry. In fact, we were doing a presentation the other day where during part of the presentation two of the people in the meeting that we were presenting to were doing stuff on their BlackBerry, so it says, "Well, how important am I?" right? Having said that, I guess it depends, on the other hand, what your role is and what you're using it for. You could be waiting for an important update for the meeting, or your role in the meeting is not significant. ...So I think it's a question of knowing why somebody's doing it. If they're doing it just because it's there and it buzzed, well, that's rather silly. (CEO, technology)

The BlackBerry "buzz" (a vibrating notification of new e-mail) causes many users to stop what they're doing and grab for their BlackBerry. More experienced users are generally less inclined to react immediately, and some do choose to turn this notification mechanism off completely. For many though, the BlackBerry takes precedence over whatever else the user is doing. A non-user finds this extremely annoying.

I have been in conversations with people and Blackberries go off, and people will stop the conversation with me to read a BlackBerry which they somehow think is now more important. ... There's a rudeness issue or a communications effectiveness issue there.

Like other mobile communication devices, BlackBerries enable "anytime, anywhere" connectivity. Our respondents reported using their BlackBerries on the golf course, on the beach, on airplanes, trains and buses, and while driving their vehicles or riding their bicycles. One tells of a phone conversation he had with his doctor wife.

"I was just seeing a patient," and I said, "Uh huh?" and she said, "The patient said that he was walking into the clinic to see me half an hour ago and he saw you riding your bike down the street with your BlackBerry in one hand and a cup of Tim Horton's coffee in another." "Really?" Are you sure?" "Oh, yeah, he was very sure." (Communications consultant)

A management consultant noted the hazards of walking around the underground path in Toronto's business district.

I haven't hit anybody yet walking and using it, but I've come very close. And I've been hit by BlackBerry users - I don't know if you have - in the underground. It happens fairly frequently. You don't get hurt, it's just, like, surprising. 
Many respondents reluctantly admitted that they used their BlackBerries when driving. In my defence, I usually wait until I come to a stop sign, or a light of some sort, but I have a very specific routine. I have a hands-free for my cell, so I'm usually on the phone as well. ... The BlackBerry's right beside me in the compartment that runs along the driver's door, so that when it vibrates and I can hear it and then I know whether or not I've got a message, and then usually I will - I admit - next time I come to a stop I will access it. I have been known to access it while I'm driving on the highway. (public security)

Our data show that BlackBerry users are constantly negotiating contradictory expectations and behaviours engendered by their devices. The benefits of always on communication are highly valued, but there are times when being disconnected is important yet it is not easy for all users to disconnect. The device allows for immediate responses to email, but in responding immediately users disengage from whatever else they are currently doing. The issue of BlackBerry usage in meetings generates much discussion, with some users reporting that their organizations have banned the devices in meetings, and others indicating that their organizational norm is to allow full usage at any time. Users know that reading and responding to e-mail while walking, cycling or driving is not a good idea, yet find themselves doing it anyway. In summary, we find that very real, serious tensions exist for BlackBerry users as they try to negotiate appropriate ways of using their devices to do their jobs, in environments where their devices are not always appropriate or embraced.

Our data have confirmed the anecdotal evidence about BlackBerry usage reported on in the popular press, and provide us an opportunity to further investigate how the BlackBerry users participating in this study manage their devices on a day to day basis.

\subsection{How do users manage their BlackBerries to address the inherent contradictions of their use?}

The BlackBerry and Treo users we spoke with indicated that they were well aware of the addictive nature of the devices, using terms like "Pavlovian" and "Crackberry" to describe their "habit". But in digging further into their opinions on BlackBerry usage, it is not clear that it is the device itself that fuels the addiction. Instead, it appears that the BlackBerry and Treo support a style of work and communication that many users had adopted long before they began using mobile communication devices.

Our data show three ways in which the BlackBerry supports our respondents' desired work patterns. The first is that the BlackBerry makes it easier for users to multi-task, by providing a silent, unobtrusive mechanism to connect to e-mail in situations where other communication forms are inappropriate, effectively allowing users to do more work in a given time period. The second is that the device connects the user to his or her office from anywhere, extending the geographic reach of work. The third means of supporting work practices is that the BlackBerry makes it easy for always on access at any time, extending the work day far beyond eight hour days. Examples of each of these ways of managing work are provided below.

\subsubsection{Multi-Tasking to Do More Work}

I was in meetings with the leader all the time and I couldn't always just answer the phone - it would have been rude to do so - but people could e-mail me and I could quietly respond to them, or find out the nature of the event so that it was often dealt with before we even left the meeting instead of getting the voicemail afterward and finding out that we hadn't... the deadline had passed, or anything like that. So, in terms of being able to respond in a timely way it was just an incredible tool. (political consultant) 
It just allows you to multi-task. I'm not doing it now but I have in other circumstances where I'd be on a conference call and I'd be BlackBerrying at the same time. Not perhaps the best thing to admit, but the fact of the matter is if you're on a conference call for a conference call that's going to take two hours, and you know where your parts are important and what to pay attention to and somebody's droning on, you can get an enormous amount of work done at the same time. I promise I'm not doing it now! (public security)

One user makes the point that his desire to multi-task is not new, but it is facilitated by the communications access his BlackBerry provides.

I'm one that often does try to accomplish more than one thing at the same time, so a behaviour that I had before BlackBerry that I still have as well is I often take other things into a meeting. ...that's another choice that I make during meetings from time to time, I'm just trying to productively use my time. (insurance)

\subsubsection{Working Anywhere, Working Everywhere}

Respondents explained how they took full advantage of the mobility provided by their devices, so that they could work from any location.

I can essentially carry my job on a daily basis with this thing. So if I'm, say, at a doctor's appointment and I'm away for the afternoon, I can not miss a beat if I have my BlackBerry because I can contact anybody I want and get answers to anything I want on this. (professional sports)

I go down to Australia for ten days I don't even tell the chairman of the board I'm gone, because I'm as available as I would have been if I were here. ...He's in Montreal. I didn't see him for ten days. I usually don't see him for ten days so what difference did it make? (insurance)

One user commented repeatedly on the value of having his e-mail "follow" him.

I have a young family ... with my e-mail following me around, I don't have to hover around my computer all the time. This allows me to spend time with my kids either in the house, outside, or at the park, without being out of touch with my e-mail. And since I can respond from anywhere, I might just have easily been at my desk. This is even true of sitting and watching a video with my kids. And for a consultant whose office is at home, this is a good thing. (political consultant)

Even when the BlackBerry is not connected to the internet, users can continue to work. For example, a couple of users discussed managing their e-mail on airplanes.

What I do is even though the function's turned off and I know I can't actually transmit, I tell it to transmit, so the moment I get off the plane all I have to do is reconnect with the tower and it just starts sending. So by the time I'm in the taxi ready to do more e-mails, going to where I'm going or make phone calls confirming where I'm going, etc., all those e-mails are gone ... (lawyer)

The geographic reach of the BlackBerry allows people to choose where they want to do their work. For some, the device has allowed them to work away from their offices at vacation properties.

I plan to be working at the cottage tomorrow, and if my boss and I have some things we need to talk about and he needs to get a message to me he knows that just by sending me an e-mail I'm going to be able to. One of the most important things for me when I got it was is it actually going to work from there, ... and it works great. But it doesn't intrude on the private space, I don't find. (VP, insurance) 


\subsubsection{Always On Access}

The BlackBerry users we spoke with work in the evening, on weekends, and while on holiday. Many commented that this is the way they have worked for years, and noted that managing their work by e-mail when they choose is a good option for them.

I find that I'll often have some free space in the evening when my wife and I will just be doing completely different things, and it's become fairly common for me to flip it on like maybe 10:30 in the evening, and I might have had some replies to things and reply then. I sometimes wonder if people think am I replying at strange times, but I'm actually just replying at a time - and occasionally even sending - that works for me. (insurance industry)

An IT consultant indicated that he has "conversations all the time with my boss at 10 or 11 o'clock at night, with the BlackBerry." Asked about using the device on weekends, his response was "we're still a small company, ... so communication is very important with us." About a third of our respondents took their BlackBerries on holiday with them.

When I'm on holidays I don't really have a holiday, but I live with a BlackBerry in my... this job isn't work to me, so I don't separate work and holidays, I'm away doing other stuff, right? So we're down in Vegas and my wife, she's out shopping here, while I'm having a coffee sitting in the mall looking stupid, so I can respond back to stuff and it makes me feel less guilty for being away. (university administrator)

In summary, our respondents were generally very positive about how they have incorporated their BlackBerries into their work and life environments. The users were certainly aware of the potentially distracting and intrusive nature of using their BlackBerries to multi-task, work anywhere, and work at anytime, but were willing to negotiate with those around them to allow them to manage their work in ways they chose. Words like "empowering" and "liberating" describe the attitude toward the device, balanced with a recognition that "discipline" in usage was important.

On a personal side, I love the work I do, I would be available 24 hours. And that's a personal issue, and that's difficult for my wife, and we have talked about this for twenty years, so this is an issue. So I have to respect our relationship and find the right balance. And the BlackBerry is enormously empowering to me, but I have to find out how to make that also fit into my personal life. (insurance)

\section{Discussion}

This paper set out to explore some of the apparent contradictions inherent in working in an environment where mobile devices allow users to be connected to their work from anywhere, at anytime. The paper focuses on a specific device, the BlackBerry, and offers BlackBerry users' perspectives on connectivity.

A key finding of this research is that these BlackBerry users have embraced the connectivity the device offers to them. The BlackBerry delivers exactly what it and other mobile devices promise: connection to others from anywhere, at any time. Although they recognize the disadvantages that always on connectivity can create, the users repeatedly reinforced the conclusion that having access to a mobile device allows them more control over their environment, and allows them to manage the heavy demands of their work in ways that best suit them. For our respondents, always on connectivity is a necessary fact of life. The always on connectivity can be intrusive and disrupting at times, but the users accept this as a part of their work environment. (In contrast, the two non-users included in the study 
made it very clear they were unwilling to make themselves available to this extent, choosing to limit their availability to the confines of mobile phones.)

In response to claims that the BlackBerry is addictive, the data presented here suggest that the device merely supports existing behaviours that require (or construct a perceived need for) constant access to information. The BlackBerry and other mobile devices make it possible for people to work all the time, but what are the personal and organizational impacts of this situation? To what extent do mobile devices exacerbate problems of workaholism and employee stress? This is an important question and one that should be addressed further. Another question of interest relates to the impacts of shifting organizational communication away from multiple modes (voice, face to face, text) in favour of an environment where the main mode of communication is e-mail.

It is noted that certain features of the BlackBerry do appear to be distinct from other mobile devices that offer similar functionality. The high reliability and ease of use of the device has allowed users to be very responsive to incoming e-mail communication. In the Canadian context, there appear to be emerging expectations that a BlackBerry user is available at anytime, and that he or she will respond more quickly to a "BlackBerry" (e-mail sent to the device) than to communication by mobile phone or "regular" e-mail. Those who choose to adopt BlackBerries are familiar with these expectations and apparently willing to conform with them.

BlackBerries are becoming more common in the US, and are now available throughout Europe, Asia and Australia. This paper provides a Canadian perspective on BlackBerry usage, but cannot predict whether similar adoption patterns will occur elsewhere. It appears that the keys to understanding this relate to users' demands for reliable, easy to use e-mail access. The BlackBerry has been successful in North America because it filled this need when there were few other alternative devices available. In markets elsewhere in the world, mobile phones and PDAs have offered access to e-mail for some time, and SMS messaging is widely used. Research in Motion, the makers of BlackBerry, indicate that they do not intend to extend the functionality of the device to compete with full-featured PDAs thus the question remains whether there is a worldwide market for a device designed primarily to manage mobile e-mail.

\section{Conclusions and Future Research}

This paper presents rich data showing how our respondents incorporate a mobile communication device into their work environment. The paper presents a picture of people who are constantly connected to their work and use their mobile devices to manage their time and interaction with others. The data presented here provide a starting point for further investigation of a series of questions about mobility in general, and specific questions about the adoption of a mobile device that offers limited functionality when compared to other devices available in the market. The key finding is that these users have embraced the anytime, anywhere connectivity mobile devices enable, valuing the ability to better control the heavy demands of their jobs. This research provides a foundation for further investigation of the work practices of employees in organizations that have adopted mobile devices like BlackBerries.

The study concentrated specifically on the use of Blackberry devices. The study however highlight a need for the development and examination of the effect any time anywhere access has on the day to day life of users. Kakihara and Sorenson (2001) highlight the social implication of the use of mobile technology. The findings of the Blackberry study needs to be evaluated in terms of existing models (such as the one developed by Kakihara and Sorenson, (2001)) to expand the understanding of the impact of these devices. 


\section{References}

Applewhite, A. (2002). The BlackBerry Business. IEEE Pervasive Computing, 1(2), 4-7.

Avery, S. (2005, 19 April). When It Comes to BlackBerry, RIM Feels the Sky's the Limit. Globe and Mail, p. B6.

BBC News. (2005). MPs Issued with BlackBerry Threat. Retrieved 14 February, 2005, from http://news.bbc.co.uk/2/hi/uk_news/politics/4254271.stm.

Churchill, E. F., \& Wakeford, N. (2002). Framing Mobile Collaborations and Mobile Technologies. In Brown, B., Green, N. \& Harper, R. (Eds.), Wireless World: Social and Interactional Aspects of the Mobile Age (pp. 154-179). London: Springer-Verlag.

Dunnavant, S. T. (2001). Blackberries in Support of Technology. Paper presented at the ACM SIGUCCS Conference on User Services, Portland, OR.

Elderfield, A. (2003). Enchanted Mobility? The Impact of New Mobile Technologies on Social Interaction. Retrieved 3 March, 2005, from http://www.cogs.susx.ac.uk/lab/hct/hctw2003/papers/elderfield.pdf.

Gibson, J. (2005, 10 February). G2: Always on My Mind: Alastair Campbell Inadvertently Fired Off an Abusive Email to Newsnight with His. Nicola Horlick Was Spotted Using Hers in Church. And Easyjet's Stelios Reputedly Checks His in Bed. Janine Gibson Also Has a BlackBerry and Offers a Cautionary Tale of Life with the Latest Executive Tool. The Guardian, p. 2.

International Telecommunication Union. (2004). The Portable Internet. Geneva: ITU.

Libin, K. (2001). Pop Goes BlackBerry: As Wireless Messaging Goes Consumer, Research in Motion Faces Stiff Competition. Canadian Business, 74, 47.

Nah, F. F.-H., Siau, K., \& Sheng, H. (2005). The Value of Mobile Applications: A Utility Company Study. Communications of the ACM, 48(2), 85-90.

Research in Motion. (2004). Annual Report. Retrieved 14 February, 2005, from http://www.rim.com/investors/pdf/2004rim_ar.pdf.

Saunders, D. (2005, 6 April). Papal Rites, Circa 2005, Shed Mystic Traditions. Globe and Mail, p. A1.

Shaw, R. (2005). Killer Date: BlackBerry 7510 from Nextel Featured on Last Night's CSI:Miami. Retrieved 23 April, 2005, from http://www.bbhub.com/2005/04/19/killerdate-BlackBerry-7510-from-nextel-featured-on-last-nights-csi-miami/.

Kakihara, M., Sørenson, C. (2001). Mobility reconsidered: Topological aspects of interaction. Proceedings of the 24th Information Systems Research Seminar in Scandinavia, Ulvik in Hardinger, Norway, 11-14 August 2001.

Tugend, A. (2004). BlackBerry Jam. Retrieved 14 February, 2005, from http://www.govexec.com/features/1104-01/1104-01s2.htm. 